\title{
Engineering in SnS-Based Solar Cell for an Efficient Device with Nickel Oxide (NiO) as the Hole Transport Layer
}

\author{
Shivendra Pratap Ray', Sadanand ${ }^{1}$, Pooja Lohia ${ }^{2}$, D. K. Dwivedi ${ }^{1, *, \infty(0)}$
}

Due to the versatility, non-toxicity and earth abundancy of raw material, SnS has considered a very useful semiconductor material and the harvesting of photovoltaic energy from this kind of semiconductor material is comparatively easier than others since it is highly efficient and costeffective. The simulation of a unique combination of device structure (ITO/SnO $/ \mathrm{SnS} / \mathrm{NiO} / \mathrm{Mo}$ ) has been done and found to be worthful. Past work is quite good but unable to achieve the standard of enhanced open-circuit voltage along with the power conversing efficiency as well. The use of Hole Transport Layer (HTL) has remarkable too, since surface recombination has fallen sharply. The PCE hiked by $25 \%$ to $27.62 \%$ regardless of it is practically unattainable but in reality, it will prove as a milestone in this area if and only if we are using HTL as well. The different HTL layer has been studied for the proposed device structure and elaborated well. For the benefit of mankind, it is completely low cost and useable along with quite good performance.

\section{Introduction}

Solar power is described as the direct conversion of solar energy into electricity using photovoltaics (PV), indirect conversion using concentrated solar power, or a combination of both. No doubt we are facing gigantic challenges regarding the existence of non-renewable resources and to remove the dependency on non-renewable resources we need to harvest sufficient energy from renewable resources. The good thing about $\mathrm{Si}$ is that it is an earth-abundant and non-toxic nature. For bulk production of energy solar cells might be good enough to take into account since the nature of earth-abundant, cost-effective and non-toxicity make it too close to work in this area [1]. The universality of sun energy is profoundly appreciable in this era however we are supposed to say the conventional source of energy will be over, with time. $\mathrm{SnS}$ films have inherited sundry fruitful properties including a relevant bandgap of $1.3 \mathrm{eV}$. Semiconductor-based device manufacturing is difficult, but solar cell physics plays an important role in making human life simpler and more comfortable.

\footnotetext{
'Amorphous Semiconductor Research Lab, Department of Physics and Material Science, Madan Mohan Malaviya University of Technology, Gorakhpur 273010, India

2Department of Electronics and Communication Engineering, Madan Mohan Malaviya University of Technology, Gorakhpur 273010, India

*Corresponding author:

E-mail: todkdwivedi@gmail.com; Tel.: (+91) 9415712163
}

Concerning production costs, $\mathrm{SnS}$-based solar cells are relatively simple to manufacture. The absorber layer is having a wide bandgap, approximately $1.3 \mathrm{eV}$ [2] which is quite suitable in photovoltaic devices and the absorption coefficient is approximately $10^{5} \mathrm{~cm}^{-1}$. This is enormously and widely used for fabricating devices such as gas sensors and transistors [3-6] along with photovoltaic cells.

In the past few years, we had very fluent work in this domain to solve the problem that the world is about to face in the coming few more decades ahead. A lot of simulation work has been proposed, which might be significant in the upcoming era [2]. However, the most favourable simulation efficiency is analyzed $25.01 \%$ for device structure ITO $/ \mathrm{CeO}_{2} / \mathrm{SnS} / \mathrm{NiO}$ of $\mathrm{SnS}$ based solar cell [3].

Although $\mathrm{SnO}_{2}$ is another hopeful electron transport layer in $\mathrm{SnS}$ based solar since it has stupendous possessions of tunable bandgap from $3.5 \mathrm{eV}$ to $3.9 \mathrm{eV}$ [4]. The use of ETL in form of $\mathrm{SnO}_{2}$ is also very interesting which is coated by sol-gel dip-coating which is eloquent [5]. There is another p-type material that is enhancing the performance of the complete cell as $\mathrm{NiO}$. It is consisting of a high work function extrinsic semiconductor material having a $3.8 \mathrm{eV}$ bandgap [6].

In the present work, $\mathrm{SnS}$ based solar cell of the device structure of ITO/ $\mathrm{SnO}_{2} / \mathrm{SnS} / \mathrm{NiO} / \mathrm{Mo}$ has been studied. The various parameters of the solar cell have been varied to optimize the performance of the solar cell. A significant improvement of the device performance has been observed which could prove to be efficient solar cell experimentally as well.

DOI: 10.5185/amlett.2021.091664 


\section{Solar cell structure and material properties}

The proposed 3D schematic design is shown in Fig. 1. A solar cell capacitance simulator in one dimension (SCAPS1D) has been used to perform the whole simulation. SCAPS software was developed by the Department of Electronics and Information Systems, University of Gent. All data is taken from Table $\mathbf{1}$ and the absorption coefficient parameter is used from the literature. $[\mathbf{1 , 7 , 8}]$. Table 2 is showing the defect at interfaces ITO/ $\mathrm{SnO}_{2} / \mathrm{SnS} / \mathrm{NiO} / \mathrm{Mo}$ solar cells.

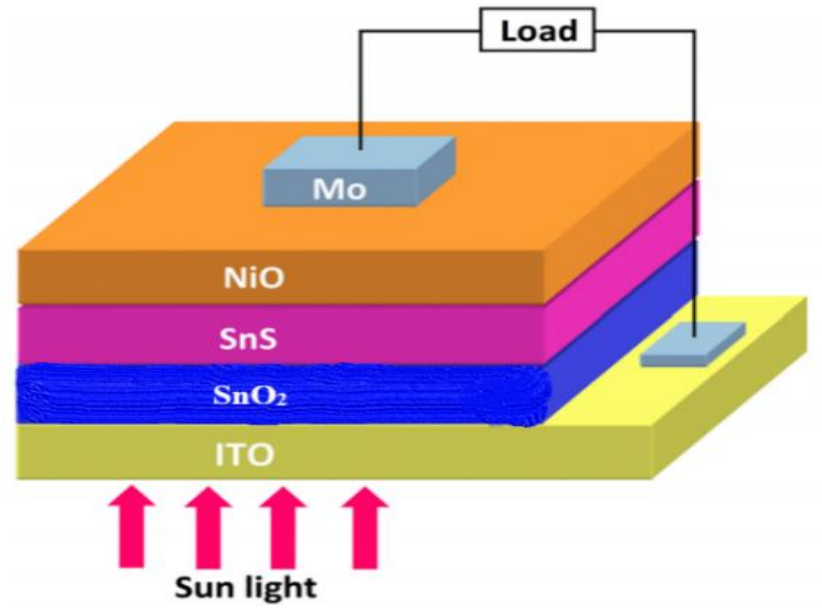

Fig. 1. The schematic device structure of the solar cell.

Table 1. Simulation parameters of the solar cell device structure [3-4,9].

\begin{tabular}{lcccc}
\hline Parameters & ITO & SnO $_{2}$ & SnS & NiO \\
\hline Thickness $(\mathrm{nm})$ & 100 & 0.7 & 1450 & 110 \\
$\mathrm{E}_{\mathrm{g}}(\mathrm{eV})$ & 3.61 & 3.61 & 1.32 & 3.82 \\
$\chi(\mathrm{eV})$ & 4.55 & 4.55 & 4.25 & 1.45 \\
$\varepsilon_{\mathrm{r}}$ & 8.95 & 9 & 12.9 & 10.0 \\
$\mathrm{~N}_{\mathrm{c}}\left(\mathrm{cm}^{-3}\right)$ & $2.20 \times 10^{18}$ & $2.20 \times 10^{18}$ & $1.18 \times 10^{18}$ & $2.80 \times 10^{18}$ \\
$\mathrm{~N}_{\mathrm{v}}\left(\mathrm{cm}^{-3}\right)$ & $1.2 \times 10^{19}$ & $1.2 \times 10^{19}$ & $4.75 \times 10^{18}$ & $1.1 \times 10^{19}$ \\
$\mu_{\mathrm{e}}\left(\mathrm{cm}^{2} / \mathrm{V}_{\mathrm{s}}\right)$ & 10 & 100 & 140 & 13 \\
$\mu_{\mathrm{p}}\left(\mathrm{cm}^{2} / \mathrm{V}_{\mathrm{s}}\right)$ & 10 & 25 & 4.2 & 2.7 \\
$\mathrm{~N}_{\mathrm{D}}\left(\mathrm{cm}^{-3}\right)$ & $10^{21}$ & $10^{20}$ & 0 & 0 \\
$\mathrm{~N}_{\mathrm{A}}\left(\mathrm{cm}^{-3}\right)$ & 0 & 0 & $10^{15}$ & $10^{21}$ \\
$\mathrm{~V}_{\text {th }} \mathrm{e}^{-}(\mathrm{cm} / \mathrm{s})$ & $10^{7}$ & $10^{7}$ & $10^{7}$ & $10^{7}$ \\
$\mathrm{~V}_{\text {th }} \mathrm{p}(\mathrm{cm} / \mathrm{s})$ & $10^{7}$ & $10^{7}$ & $10^{7}$ & $10^{7}$ \\
Defect & 0 & $10^{14}$ & $10^{14}$ & $10^{14}$ \\
density $\left(\mathrm{cm}^{-3}\right)$ & & & & \\
Radiative & 0 & $2.3 \times 10^{-9}$ & $2.3 \times 10^{-9}$ & $2.3 \times 10^{-9}$ \\
recombination & & & & \\
coefficient $\left(\mathrm{cm}^{3}\right.$, & & & & \\
\hline
\end{tabular}

Table 2. Listed data for interface defect in $\mathrm{ITO} / \mathrm{SnO}_{2} / \mathrm{SnS} / \mathrm{NiO} / \mathrm{Mo}$ cell.

\begin{tabular}{|c|c|c|}
\hline Parameters & $\mathrm{NiO} / \mathrm{SnS}$ interface & $\mathrm{SnO}_{2} / \mathrm{SnS}$ interface \\
\hline Defect type & Neutral & Neutral \\
\hline $\begin{array}{l}\text { Energy for Reference } \\
(\mathrm{eV})\end{array}$ & 0.06 & 0.06 \\
\hline $\begin{array}{l}\text { Reference for defect } \\
\text { energy level } E_{t}\end{array}$ & $\begin{array}{l}\text { above the highest } \\
\qquad E_{v}\end{array}$ & above the highest $E_{v}$ \\
\hline $\begin{array}{l}\text { Capture cross- } \\
\text { section holes }\left(\mathrm{cm}^{2}\right)\end{array}$ & $1.0 \times 10^{-19}$ & $1 \times 10^{-19}$ \\
\hline $\begin{array}{l}\text { Capture cross section } \\
\text { electrons }\left(\mathrm{cm}^{2}\right)\end{array}$ & $1.0 \times 10^{-19}$ & $1 \times 10^{-19}$ \\
\hline
\end{tabular}

\section{Results and discussion}

\section{Analysis of the nature of $\mathrm{SnO}_{2}$ and absorber layer with thickness}

The thickness of the absorber layer is one of the crucial parameters that could be optimized for better solar cell performance. The thickness of SnS absorber layer is varied from $500 \mathrm{~nm}$ to $2800 \mathrm{~nm}$. The impact of the $\mathrm{SnS}$ absorber layer is shown in Fig. 2(a-b). The $V_{\text {oc }}$ decreases with increasing thickness of SnS but $\mathbf{J}_{\mathrm{sc}}$ increases with increasing thickness of absorber layer because a maximum number of higher wavelength photon got absorbed in this layer. The FF is slightly decreasing with increasing the thickness of the absorber layer due to an increase in series resistance. The PCE of the SnS absorber layer increases with thickness and gets saturated almost after $2500 \mathrm{~nm}$ thickness of $\mathrm{SnS}$ absorber layer. The rate of carrier recombination is simply given by the relation.

$$
\frac{d n}{d t}=-k_{3} n^{3}-k_{2} n^{2}-k_{1} n
$$

In the above equation, $n$ denotes the carrier density.
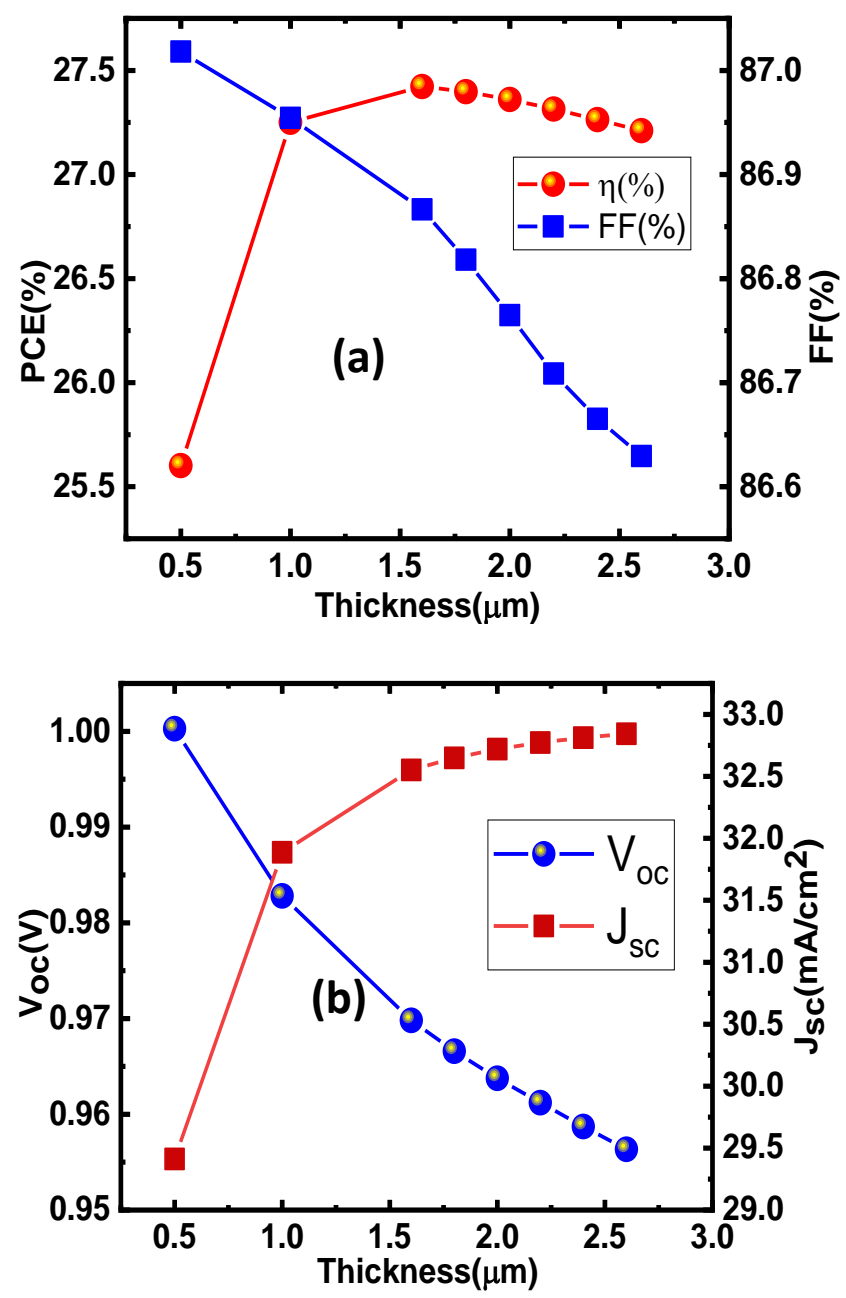

Fig. 2(a-b). Impact of the absorber layer thickness on $J_{\mathrm{sc}}, V_{\mathrm{oc}}, \mathrm{FF}$ and $\eta$. 


\section{Advanced Materials Letters https://aml.iaamonline.org}

The analysis of $\mathrm{SnO}_{2}$ electron transport material on the designed solar cell performance has been analyzed which is shown in Fig. 3. The thickness of $\mathrm{SnO}_{2}$ has been varied from $200 \mathrm{~nm}$ to $1000 \mathrm{~nm}$. The significant impact of ETL on photovoltaic performance has been observed. The electrical parameters such as $\mathrm{V}_{\mathrm{oc}}, \mathrm{J}_{\mathrm{sc}}, \mathrm{FF}$, and $\eta$ decrease with the thickness of $\mathrm{SnO}_{2}$ ETL due to sires resistance.
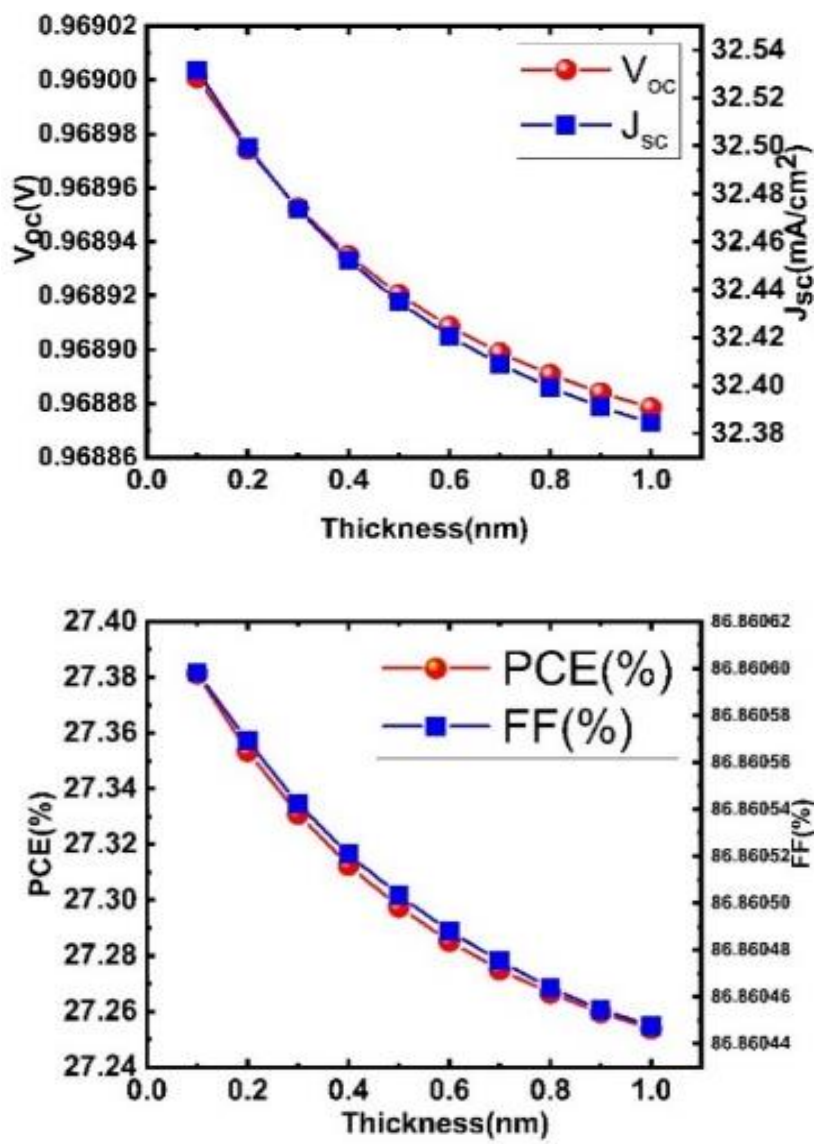

Fig. 3. Impact of the thickness of the electron transport layer on the solar cell properties.

\section{Influence of series and shunt resistance}

The impact of series resistance $\left(\mathrm{R}_{\mathrm{s}}\right)$ on solar cell performance is immense and it occurs especially from the contact among the layers which is taken and left, right metal contacts. The performance was analyzed while taking the variation of series resistance $\left(R_{\mathrm{s}}\right)$ from 2 to $30 \mathrm{ohm}-\mathrm{cm}^{2}$. Fig. 4 shows that $V_{o c}$ and $J s c$ are analyzed to be independent of $R_{s}$ after $5 \mathrm{ohm}-\mathrm{cm}^{2}$ and also seen that PCE and $F F$ are decreasing with increasing series resistance $\left(R_{s}\right)$ because power loss also increases with increasing series resistance $\left(\mathrm{R}_{\mathrm{s}}\right)$.

The shunt resistance $\left(\mathrm{R}_{\mathrm{sh}}\right)$ also plays a crucial role to improve the performance of solar cells and it can come due to manufacturing defects [10]. The shunt resistance $\left(\mathrm{R}_{\mathrm{sh}}\right)$ has been varied from 100 to $1500-\mathrm{ohm} \mathrm{cm}^{2}$ to optimize the photovoltaic solar cell performance which is shown in
Fig. 4(b). From Fig. 4(b) it is evident that on increasing shunt resistance $\left(\mathrm{R}_{\mathrm{sh}}\right)$ all parameters increase to a certain point after that they get saturated.

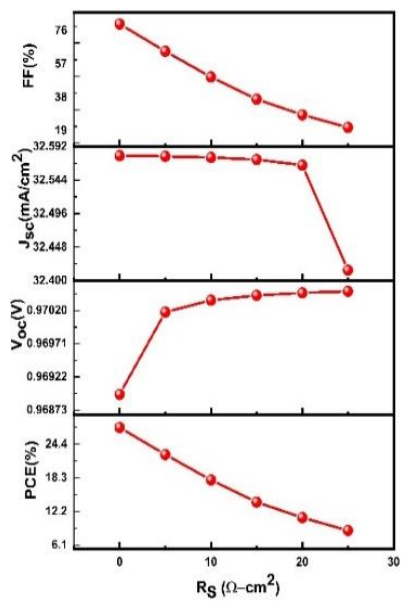

(a)

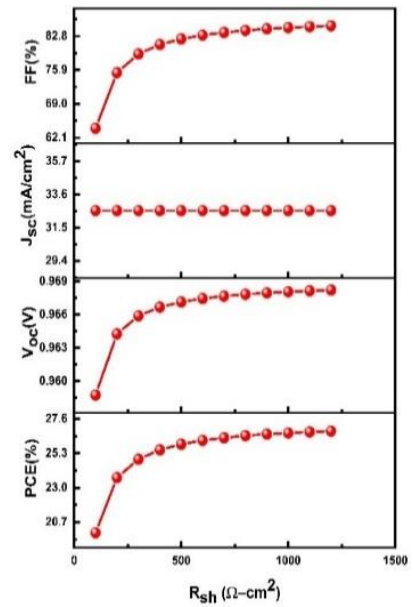

(b)
Fig. 4. Impact of (a) series $\left(\mathrm{R}_{\mathrm{s}}\right)$, and (b) shunt $\left(\mathrm{R}_{\text {sh }}\right)$ resistance on photovoltaic performance.

\section{Analysis of back contact, metal work function and working temperature}

The impact of the metal-work function on the solar cell performance has been observed which is shown in Fig. 5(a). The solar cell performance such as $\mathrm{V}_{\mathrm{oc}}, \mathrm{PCE}$, and FF increases with the increase in back contact metal work function and after a certain value of work function, they became constant. In analysis, it is found that the power conversing efficiency becomes constant at work function of value $>4.75 \mathrm{eV}$. Thus, the work function for the above design structure has been concluded that $4.5 \mathrm{eV}$.

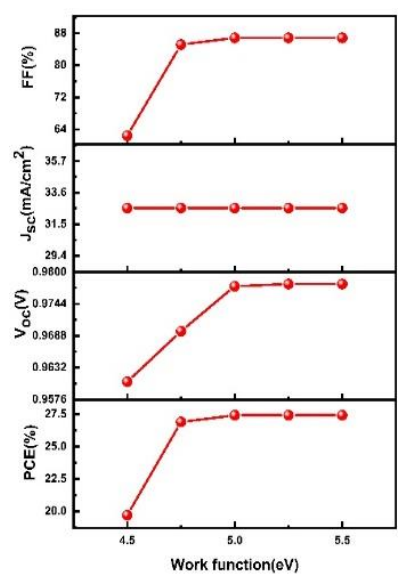

(a)

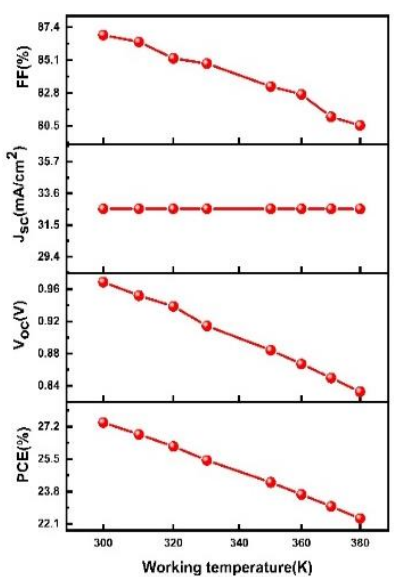

(b)
Fig. 5. Study of the variation of all solar cell parameters with (a) back contact metal work function and (b) working temperature.

The impact of the solar cell performance on the device structure of ITO/ $\mathrm{SnO}_{2} / \mathrm{SnS} / \mathrm{NiO} / \mathrm{Mo}$ has been studied which is depicted in Fig. 5(b). As we increase the 
Advanced
Materials Letters
https://aml.iaamonline.org

temperature the band energy of the charge carrier reduces which increases the velocity of the charge carrier. According to the band theory, with the reduction of band energy bandgap decreases since the collision among charge carriers and vibrational atoms get higher at a high working temperature which increases the power loss. Current density $\left(\mathrm{J}_{\mathrm{sc}}\right)$ is almost constant and not affected by working temperature however all other solar cell parameters decrease since reduction in-band energy leads to a decrease in the bandgap. Consequently, the performance of the photovoltaic solar cell at higher temperatures decreases.

\section{Analysis of NiO/SnS interface defect density}

In this section, the impact of $\mathrm{NiO} / \mathrm{SnS}$ interface defect on cell performance has been studied which is shown in Fig. 6. The defect density has been varied from $10^{10}$ to $10^{18} \mathrm{~cm}^{-2}$ of $\mathrm{NiO} / \mathrm{SnS}$ interface defect and noted the solar cell performance. The open-circuit voltage is reducing as defect density increases and current density being uninfluenced till few points and then start decreases with increases in interface defect density. The same trend is observed for PCE and FF.
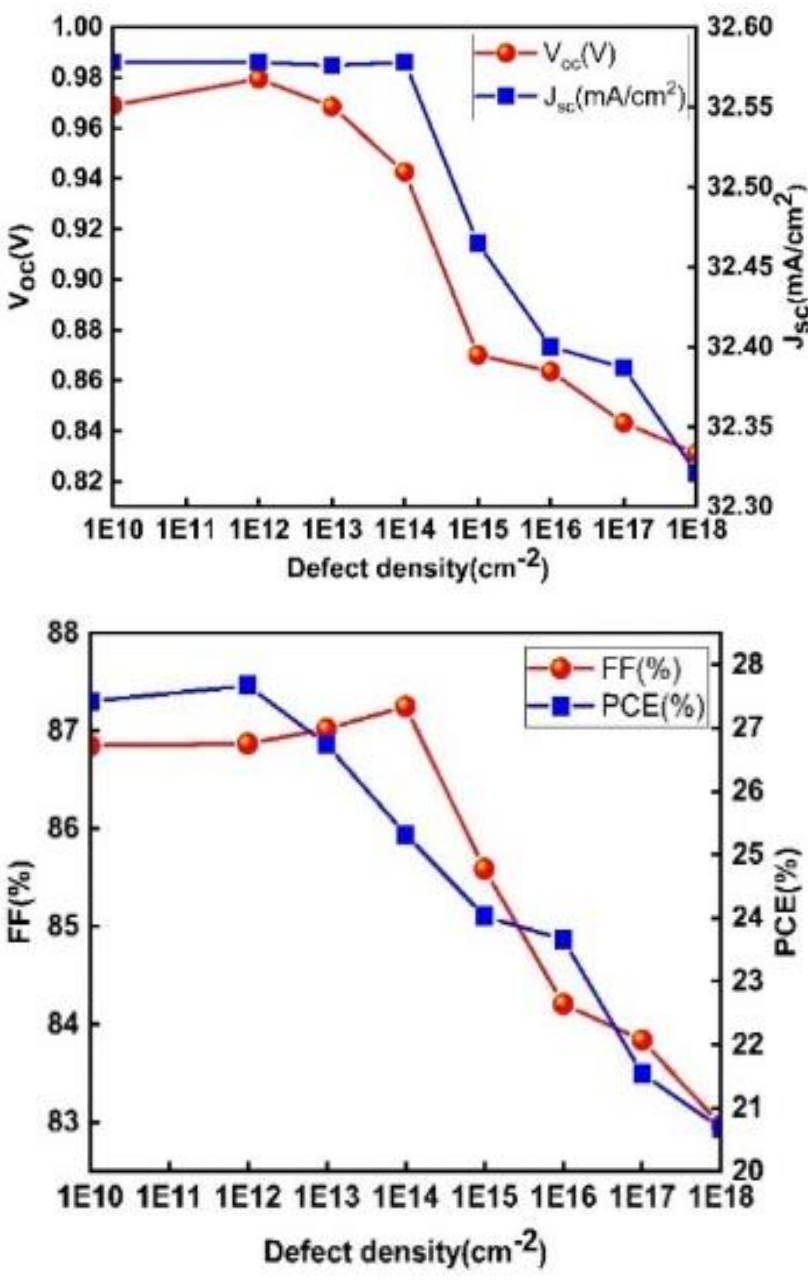

Fig. 6. Depiction of $\mathrm{NiO} / \mathrm{SnS}$ interface defect density.

\section{Effect of SnS/SnO ${ }_{2}$ interface defect density}

In this interface, the carrier trapping probability and as well as series resistance plays a significant role in device performance. The impact of the interface defect was analyzed and it is found that $\mathrm{V}_{\text {oc }}$ decreases with an increase in defect density which is shown in Fig. 7. Because with the increase in defect density, carrier recombination is increased. FF and PCE go on drastically downward which means that high defect density and series resistance $[\mathbf{1 1 , 1 2}]$.
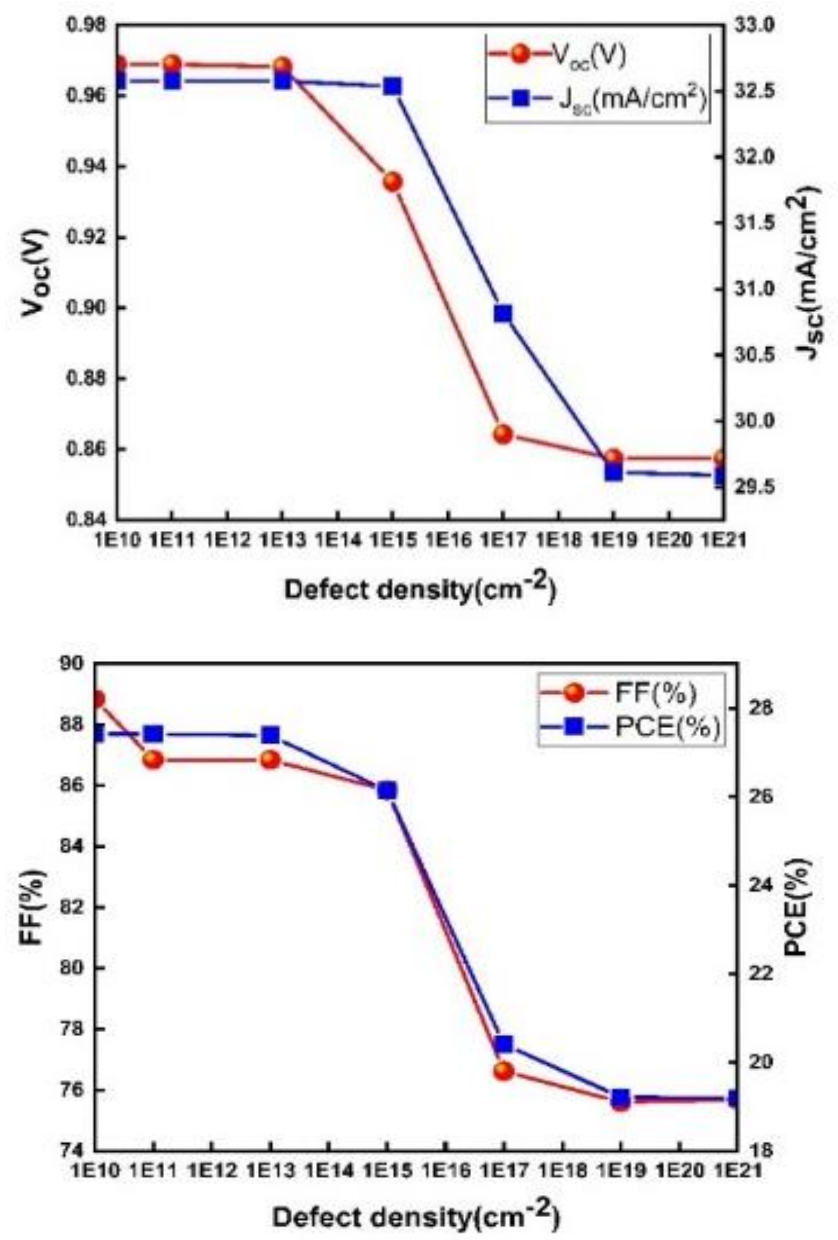

Fig. 7. Study of the impact of $\mathrm{SnO}_{2} / \mathrm{SnS}$ interface defect on solar cell performance.

\section{Impact of the absorber and $\mathrm{SnO}_{2}$ layers carrier concentration}

Carrier concentration is one of the crucial parameters of the solar cell during the design of the solar cell. The carrier concentration of the $\mathrm{SnS}$ absorber layer is varied from $10^{15}$ to $10^{18} \mathrm{~cm}^{-3}$ which is shown in Fig 8 . The open-circuit voltage is increasing with increasing carrier concentration of SnS absorber layer while current density decreasing. PCE and FF are slightly increased and then start to decrease with carrier concentration which is shown in Fig. 8. The irregular performance is observed at carrier concentration > $10^{16} \mathrm{~cm}^{-3}$ due to Auger recombination [13-16]. At a large 
value of carrier concentration of $\mathrm{SnS}$ absorber layer, the hole transportation is slightly suppressed from absorber layer to hole transport layer $(\mathrm{NiO})$.
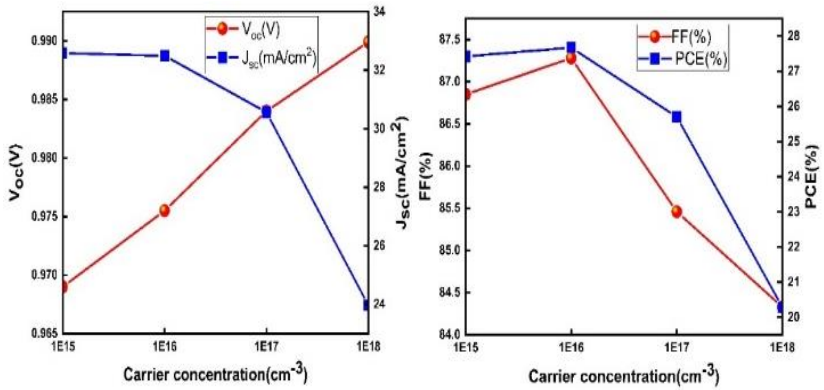

Fig. 8. Impact of the carrier concentration of absorber layer on $\mathrm{V}_{\mathrm{oc}}, \mathrm{J}_{\mathrm{sc}}, \mathrm{FF}$, and $\eta$.

The impact of the $\mathrm{SnO}_{2}$ layer concentration has been studied which is shown in Fig. 9. The carrier concentration was varied from $10^{18}$ to $10^{21}$. The variation in the carrier concentration tends to the increment in open-circuit voltage due to an increment in the photon absorption while other parameters decrease [17-21]. The increment in the carrier concentration of the ETL layer reduced the corresponding voltages due to recombination of the minority charge carrier. The FF decreases with carrier concertation because of the series resistance [22].
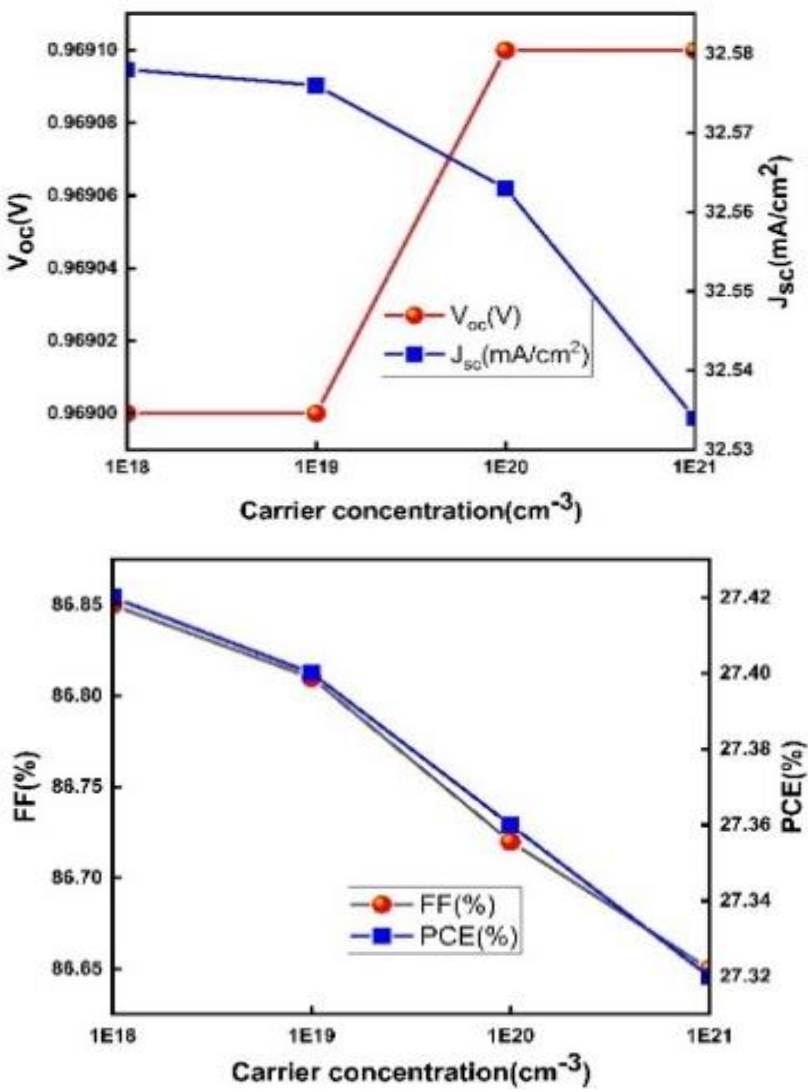

Fig. 9. Influence of the carrier concentration of the $\mathrm{SnO}_{2}$ layer on solar cell performance.

\section{Conclusion}

SCAPS-1D simulation software was used to perform the simulation of the proposed device structure (ITO/SnO $/ 2 / \mathrm{SnS} / \mathrm{NiO} / \mathrm{Mo})$. To optimize the overall performance of the solar cell impact of the various parameters has been studied. It is found that thickness and carrier concentration play a significant role in the development of efficient solar cells. The solar device is also temperature sensitive. The hole transport layer help in the enhancement of the solar cell performance in the same way as the electron transport layer does. The maximum PCE of the purposed device is $27.6 \%$ observed which could prove to be an efficient thin-film solar cell experimentally.

\section{Conflicts of interest}

There are no conflicts to declare.

\section{Keywords}

Solar cell, $\mathrm{SnS}$ absorber layer, $\mathrm{SnO}_{2}, \mathrm{NiO}, \mathrm{SCAPS}-1 \mathrm{D}$.

Received: 8 April 2021

Revised: 23 May 2021

Accepted: 29 May 2021

\section{References}

1. Sinsermsuksakul, P.; Sun, L.; Lee, S. W.; Park, H. H.; Kim, S. B.; Yang, C.; Gordon, R. G.; Advanced Energy Materials., 2014, 4 1400496.

2. Koteeswara Reddy, N.; Devika, M.; Gopal, E. S. R.; Critical Reviews in Solid State and Materials Sciences, 2015, 40, 359.

3. Andrade-Arvizu, J.A.; Courel-Piedrahita, M.; Vigil-Galán, O.; Journal of Materials Science: Materials in Electronics, 2015, 26 , 4541.

4. Baek, I. H.; Pyeon, J. J.; Lee, G. Y.; Song, Y. G.; Lee, H.; Won, S O.; Kim, S. K.; Chemistry of Materials, 2020, 32, 2313.

5. Debnath, S.; Islam, M. R.; Khan, M. S. R.; Bulletin of Materials Science, 2007, 30, 315.

6. Devika, M.; Reddy, N. K.; Ramesh, K.; Patolsky, F.; Gunasekhar, K R.; Solid-state Electronics, 2009, 53, 630.

7. Xiao, D.; Li, X.; Wang, D.; Li, Q.; Shen, K.; Wang, D.; Solar Energy Materials and Solar Cells, 2017, 169, 61.

8. Ghodsi, F. E.; Tepehan.; Physica Status Solidi (A), 2006, $203,526$.

9. Hossain, M. I.; Alharbi, F. H.; Tabet, N.; Solar Energy, 2015, 120 370.

10. Kumar, S. G.; Rao, K. K.; Energy \& Environmental Science, 2014, 7, 45 .

11. Lee, H.; Yang, W.; Tan, J.; Park, J.; Shim, S. G.; Park, Y. S.; Moon, J.; ACS Applied Materials \& Interfaces, 2020, 12, 15155.

12. Menaka, S. M.; Umadevi, G.; \& Manickam, M.; Materials Chemistry and Physics, 2017, 191, 181.

13. Minbashi, M.; Ghobadi, A.; Ehsani, M. H.; Dizaji, H. R.; \& Memarian, N.; Solar Energy, 2018, 176, 520.

14. Miyawaki, T.; Ichimura, M.; Materials Letters, 2007, 61, 4683.

15. Moon, M. M. A.; Ali, M. H.; Rahman, M. F.; Hossain, J.; Ismail, A. B. M.; Physica Status Solidi (A), 2020, 217, 1900921.

16. Wang, L.; Han, Z.; Zhao, Q.; Yao, X.; Zhu, Y.; Ma, X.; ... \& Cao C.: Journal of Materials Chemistry A, 2020, 8, 8612

17. Wang, L.; Zhao, Q.; Wang, Z.; Wu, Y.; Ma, X.; Zhu, Y.; Cao, C.; Nanoscale, 2020, 12, 248.

18. Wolfe, C. M.; Holonyak Jr, N.; \& Stillman, G. E.; Physical Properties of Semiconductors. Prentice-Hall, Inc. 1988.

19. Zhang, L.; Jiang, C.; Wu, C.; Ju, H.; Jiang, G.; Liu, W.; Chen, T.; ACS Applied Materials \& Interfaces, 2018, 10, 27098.

20. Sadanand, Dwivedi D. K.; Sol. Energy, 2019, 193, 442.

21. Minbashi, M.; Ghobadi, A.; Ehsani, M. H.; Dizaji, H. R.; Memarian, N.; Solar Energy, 2018, 176, 520.

22. Sadanand; Babu, P. S. et al.; Optik, 2021, 229, 166235. 